\title{
PAPILIONOIDEAE (LEGUMINOSAE) ARBÓREAS E LIANAS NA ESTAÇÃO DE PESQUISA, TREINAMENTO E EDUCAÇÃO AMBIENTAL (EPTEA), MATA DO PARAÍSO, VIÇOSA, ZONA DA MATA MINEIRA ${ }^{1}$
}

\author{
Izabella Martins da Costa Rodrigues ${ }^{2}$ e Flávia Cristina Pinto Garcia ${ }^{3}$
}

\begin{abstract}
RESUMO - Este trabalho consiste em um levantamento florístico das árvores e lianas pertencentes à Papilionoideae da Mata do Paraíso, importante fragmento de Floresta Estacional Semidecidual Submontana, no Município de Viçosa, Zona da Mata mineira. A pesquisa de campo foi realizada por meio de visitas à área de estudo, no período de julho/2004 a agosto/2005. Foram reconhecidos 12 táxons infra-específicos pertencentes a oito gêneros, sendo Machaerium Pers. (4 spp.) e Dalbergia L. f. (2 spp.) os mais representativos. São apresentados chaves de identificação, descrições, ilustrações e comentários sobre os táxons analisados. Dalbergia nigra (Vell.) Allemão ex Benth., espécie vulnerável, e Ormosia vicosana Rudd, endêmica da região, foram encontradas na EPTEA.
\end{abstract}

Palavras-chave: Papilionoideae, Florística e Floresta Estacional Semidecidual.

\section{TREES AND LIANES OF THE PAPILIONOIDEAE (LEGUMINOSAE) IN THE RESEARCH, TRAINING AND ENVIRONMENTAL EDUCATION STATION (EPTEA), MATA DO PARAíSO, VIÇOSA, ZONA DA MATA MINEIRA}

\begin{abstract}
This work is a floristic survey of trees and lianas of the Papilionoideae in the Mata do Paraíso, an important fragment of Submontane Semideciduous Seasonal Forest, in Viçosa, Zona da Mata Mineira. The fieldwork was carried out through visits to the studied area, from July/2004 to August/2005. Twelve taxa represented by eight genera were recorded. Machaerium Pers. (4spp.) and Dalbergia L.f. (2 spp.) were the most representatives. Identification keys, descriptions and illustrations are presented for the analyzed taxa. Dalbergia nigra (Vell.) Allemão ex Benth., vulnerable species and, Ormosia vicosana Rudd, endemic for the region were found at EPTEA.
\end{abstract}

Keywords: Papilionoideae, Floristic survey and Semideciduous Seasonal Forest.

\section{INTRODUÇÃO}

A Mata do Paraíso, situada na Estação de Pesquisa, Treinamento e Educação Ambiental (EPTEA), consiste de um fragmento remanescente de Floresta Estacional Semidecidual Submontana localizado no Município de Viçosa, Zona da Mata mineira. Assim como outras formações vegetacionais do país, a Estação apresenta um histórico de degradação decorrente da retirada de madeira, exploração de pedreira e práticas agrícolas inadequadas, como monocultura do café e uso de pastagens (VOLPATO, 1994). Segundo Leal-Filho (1992), encontra-se em estádio de regeneração.

A região de Viçosa é considerada de importância biológica muito alta, sendo prioritária para a conservação da flora (DRUMMOND et al., 2005). A maioria dos trabalhos sobre a composição florística e estrutura

\footnotetext{
${ }^{1}$ Recebido em 20.02.2006 e aceito para publicação em 21.11.2006.

${ }^{2}$ Bolsista PIBIC/CNPq - UFV. E-mail: <izabellamcr@yahoo.com.br>.

${ }^{3}$ Departamento de Biologia Vegetal da UFV, Av. P.H. Rolfs, s/no , Campus Universitário, 36.570-000 Viçosa-MG. E-mail:<fcgarcia@ufv.br>.
} 
da comunidade vegetal, realizados em fragmentos florestais dessa região, relata a importância de Leguminosae, em especial de Papilionoideae (SILVA et al., 2000, 2003; MEIRA NETO e MARTINS, 2000, 2002).

Papilionoideae é a maior subfamília de Leguminosae e apresenta distribuição cosmopolita (LEWIS, 2005). Está representada por ervas, subarbustos, arbustos, árvores, trepadeiras e lianas. Apresentam folhas pinadas, uni, tri ou plurifolioladas; inflorescências, em geral, racemosas ou paniculadas; flores com corola papilionácea, simetria zigomorfa e prefloração imbricada vexilar; androceu com no máximo 10 estames; gineceu uni ou pluricarpelar (POLHILL, 1981; BARROSO et al., 1991; LEWIS, 2005). Reúne 28 tribos, cerca de 483 gêneros e 13.800 espécies (WOJCIECHOWSKI, 2003; LEWIS, 2005). As tribos herbáceas são comuns em regiões temperadas, enquanto as regiões tropicais contam com maior número de espécies lenhosas (BARROSO et al., 1991; LEWIS, 2005).

Trabalhos realizados com a estrutura da comunidade vegetal da Mata do Paraíso mostraram que Papilionoideae contribuiu com seis espécies e quatro gêneros, correspondendo a um índice total de importância de 2,91\% (LEAL-FILHO,1992). O mesmo número de gêneros e espécies foi amostrado no estudo de Volpato (1994), totalizando $6,32 \%$ dos representantes do fragmento. Um estudo mais recente sobre a florística arbórea de 20,5\% da área total da Mata, correspondente à Trilha dos Gigantes, amostrou 15 espécies e 10 gêneros dessa subfamília (MARANGON et al., 2003). O levantamento florístico de Caesalpinioideae (Leguminosae), realizado na Mata do Paraíso por Corrêa e Garcia (2003), amostrou 11 espécies e sete gêneros.

Com o objetivo de continuar os estudos sobre Leguminosae na EPTEA, foi realizado, neste trabalho, o estudo taxonômico de Papilionoideae, sendo apresentadas descrições, ilustrações e chave analítica para a identificação dos táxons arbóreos e lianas amostrados.

\section{MATERIAL E MÉTODOS}

A EPTEA, Mata do Paraíso (Figura 1), abrange uma área de 194,36 ha, no Município de Viçosa, $20^{\circ}$ $45^{\prime} \mathrm{S}$ e $42^{\circ} 55^{\prime} \mathrm{W}$, Zona da Mata mineira, com altitude de 689,73 m (VOLPATO, 1994). É administrada pelo Departamento de Engenharia Florestal da Universidade
Federal de Viçosa. O clima, segundo a classificação de Köppen, é do tipo $\mathrm{C}_{\mathrm{wb}}$, tropical de altitude, com verões quentes e chuvosos e invernos frios e secos (CASTRO, 1980). A vegetação pode ser identificada segundo a classificação de Veloso et al. (1991), como Floresta Estacional Semidecidual Submontana. Encontrase em diversos estádios sucessionais de desenvolvimento, não tendo sido realizados registros de incêndio ou extração de madeira desde 1963 (LEALFILHO, 1992). De acordo com Rizzini (1992), essa vegetação faz parte dos domínios da Floresta Atlântica.

As coletas de material botânico e observações de campo foram realizadas em visitas mensais à área de estudo, de julho a setembro de 2004, e quinzenais, de outubro de 2004 a agosto de 2005 . As coletas foram realizadas ao longo de trilhas já estabelecidas: a trilha principal, que corta a reserva no sentido norte-sul, o "Caminho das Águas", a "Trilha dos Gigantes" e o aceiro que circunda a área. Foram coletados ramos de indivíduos férteis e observados aspectos gerais, como: hábitos, "habitat" e ocorrência das espécies nas trilhas.

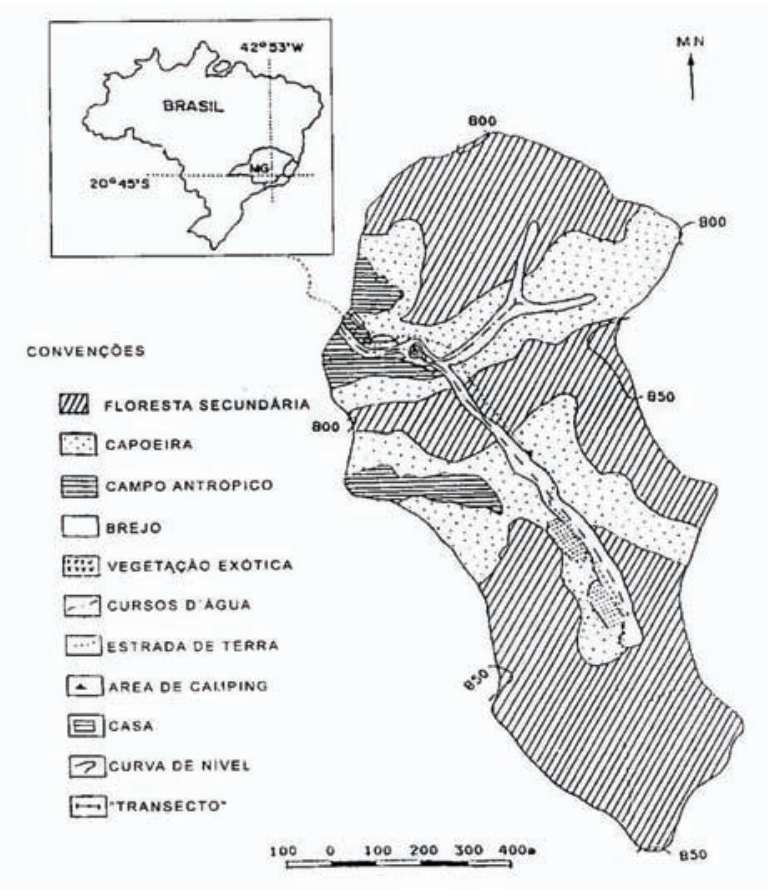

(Fonte: LESSA et al., 1999)

Figura 1 - Mapa com a localização e zoneamento da EPTEA, Mata do Paraíso.

Figure 1 - Location map of EPTEA, Mata do Paraíso, in Minas Gerais, Brazil. 
O material amostrado foi herborizado segundo as técnicas descritas por Fidalgo e Bononi (1989) e registrado no Herbário VIC, do Departamento de Biologia Vegetal da Universidade Federal de Viçosa. As flores foram fixadas em álcool 70\%, para análise morfológica e ilustração.

A identificação dos indivíduos foi realizada com base na literatura taxonômica dos gêneros e espécies encontrados, por comparação com o acervo do Herbário VIC e confirmação por especialistas. As descrições morfológicas dos táxons foram realizadas através da análise morfológica do material coletado na EPTEA, utilizando-se estereomicroscópio e empregando a terminologia de Radford et al. (1974) e da literatura taxonômica consultada. A classificação genérica está de acordo com Lewis (2005).

Após a descrição de cada táxon, são apresentados comentários abordando a distribuição geográfica, compilada na literatura, e os caracteres diagnósticos.

\section{RESULTADOS E DISCUSSÃO}

Foram reconhecidos 12 táxons infra-específicos distribuídos em oito gêneros e três tribos, e o número de gêneros e espécies foi superior ao encontrado em estudos de composição florística para a região de Viçosa: Mata da Biologia da UFV, Mata da Silvicultura e trecho de floresta da Fazenda São Geraldo (SILVA et al., 2000, 2003; MEIRANETO e MARTINS, 2000, 2002). No entanto, esse número foi inferior ao encontrado no trabalho de Marangon et al. (2003), para a Mata da Pedreira, onde foram amostradas também as espécies: Andira anthelmia (Vell.) J.F. Macbr., Bowdichia virgilioides H.B.K., Erythrina verna Vell., Machaerium triste Vogel, Machaerium aculeatum Raddi, Lonchocarpus muehlbergianus Hassl., Machaerium stipitatum Vogel e Zollernia ilicifolia Vogel. Na revisão do gênero, Andira anthelmia não foi citada para Minas Gerais (PENNINGTON, 2003); Bowdichia virgilioides é típica de Cerrado e ocorre em florestas que apresentam transição com esse bioma (LORENZI, 2002); Erythrina verna, quando jovem, apresenta folhas semelhantes à Erythrina falcata Benth., espécie amostrada neste trabalho; Machaerium triste, juntamente com essas espécies, não foi amostrado nos trabalhos de composição florística citados anteriormente para a região; Machaerium aculeatum pode ser facilmente confundida, quando estéril, com Machaerium hirtum (Vell.) Stellfeld, amostrada neste trabalho. Outras espécies como Lonchocarpus muehlbergianus Hassl., Machaerium stipitatum Vogel e Zollernia ilicifolia Vogel podem ocorrer na região, mas nenhum indivíduo, mesmo estéril, foi encontrado na área estudada. A confirmação da identificação das espécies encontradas por Marangon et al. (2003) não foi possível devido à ausência do material-testemunho no herbário citado no referido trabalho.

Dalbergieae foi a tribo mais rica, sendo representada por seis gêneros: Andira, Dalbergia, Hymenolobium, Machaerium, Platycyamus e Platypodium. Phaseoleae e Sophoreae foram representadas por apenas um gênero cada: Erythrina e Ormosia, respectivamente. Os gêneros mais representativos foram Machaerium (4spp.) e Dalbergia (2 spp.), e os restantes apresentaram uma espécie cada.

Um indivíduo de Platymiscium sp., jovem e estéril, foi amostrado neste trabalho, o que impossibilitou a identificação e, portanto, não foi aqui incluído.

\subsection{Chave para identificação de Papilionoideae arbóreas e lianas da EPTEA}

1. Folhas 3-folioladas

2. Caule armado; estipelas glanduliformes; cálice assimétrico, lacínios reduzidos; corola laranjaavermelhada

4. Erythrina falcata

2'. Caule inerme; estipelas não-glanduliformes; cálice simétrico, 5-laciniado; corola lilás.. 11. Platycyamus regnellii

1'. Folhas plurifolioladas

\section{Lianas}

4. Estípulas não observadas; folhas 913-folioladas; sâmara com núcleo seminífero central 2. Dalbergia frutescens

4'. Estípulas espinescentes; folhas 31 41-folioladas; sâmara com núcleo seminífero basal 7. Machaerium gracile

3'. Árvores

5. Folíolos opostos

6. Folhas 7-11-folioladas; folíolos elípticos, obovados ou oblanceolados, face adaxial glabra; frutos drupa ou legume

R. Árvore, Viçosa-MG, v.31, n.3, p.521-532, 2007 
7. Estipelas presentes; drupa globosa, glabra; semente alvacenta

\section{Andira fraxinifolia}

7'. Estipelas ausentes; legume elipsóide, ferrugíneo-velutino; semente bicolor.... 10. Ormosia vicosana

6’. Folhas 19-23-folioladas; folíolos oblongos, face adaxial velutina ou lanosa; fruto sâmara, região seminífera central, delimitada por duas nervuras marginais janeirense var. janeirense

5. Hymenolobium 5'. Folíolos alternos

8. Folíolos com nervação camptódroma; sâmara com núcleo seminífero distal 12. Platypodium elegans

8'. Folíolos com nervação broquidódroma ou craspedódroma; sâmara com núcleo seminífero basal ou central.

núcleo seminífero basal

9. Sâmara cultriforme,

10. Estípulas espinescentes presentes; folhas 31-49-folioladas 9. Machaerium hirtum

10'. Estípulas espinescentes ausentes; folhas com até 23 folíolos

11. Folhas 1113-folioladas; folíolos com ápice acuminado a cuspidado 6.Machaerium brasiliense

11'. Folhas 1723-folioladas; folíolos com ápice agudo a arredondado 8. Machaerium nyctitans

9'. Sâmara elípticaoblonga, núcleo seminífero central. 3.Dalbergia nigra

\subsection{Descrição dos táxons de Papilionoideae encontrados na EPTEA}

1. Andira fraxinifolia Benth., Comm. Leg. Gen.: 44. 1837. Figuras 2-6

Árvore 5-8 m alt.; caule cilíndrico, alvacentoglabrecente, ferrugíneo-puberulento no ápice, lenticelado. Estípulas 2-7 mm compr., triangulares, caducas; estipelas 1-3 mm compr., subuladas, caducas. Folhas 9-11folioladas, imparipinadas; folíolos 2,4-7,4x1-2,6 cm, opostos, elípticos, obovados a oblanceolados, base obtusa, ápice acuminado a cuspidado, face adaxial glabra, face abaxial pubescente, nervação broquidódroma. Inflorescências paniculadas, axilares; cálice 5-laciniado, 6-7 mm compr., campanulado, ferrugíneo-tomentoso externamente, lacínios regulares, arredondados; corola 5-mera, róseo-violácea, vexilo 15-19 mm compr., alas e pétalas da carena ca. $15 \mathrm{~mm}$ compr.; androceu 10mera, diadelfos (9+1), estames 11-13 mm compr.; gineceu estipitado, estípite ca. $6 \mathrm{~mm}$, ovário ca. $5 \mathrm{~mm}$ compr., pubescente, estilete ca. $4 \mathrm{~mm}$ compr., curvo, esparsamente piloso, estigma funiliforme, ciliado. Fruto drupa, 2,42,6x1,4-1,9 cm, elipsóide, lenhoso, glabro; 1 semente, 1 2,4x1,3-1,8 cm ovóide, alvacenta.

Material selecionado: BRASIL. Minas Gerais: Viçosa, EPTEA, Estrada para o Centro de Educação Ambiental, XI/2004 (fl.) Rodrigues 12 \& Basílio (VIC); I/2005 (fr.), Rodrigues 36 \& Ferreira (VIC).

Pode ser reconhecida principalmente pelo hábito arbóreo com folhas imparipinadas, estipeladas, folíolos opostos e ovário pubescente. As folhas 9-11-folioladas e os folíolos cartáceos com face abaxial moderadamente pubescente são também caracteres diagnósticos (LEWIS, 1987). Na EPTEA, foi encontrada em trilhas abertas como o aceiro, a estrada para o Centro de Educação Ambiental e a trilha principal. No Brasil, ocorre nos Estados do Ceará, Pernambuco, Alagoas, Bahia, Distrito Federal, Goiás, Região Sudeste, Paraná e Santa Catarina (PENNINGTON, 2003; LIMA et al., 1994).

2. Dalbergia frutescens (Vell.) Britton., Bull. Torrey Bot. Club 16 (12): 324. 1889.Figuras 7-9.

Pterocarpus frutescens Vell., Fl. Flumin. 302. 1829.

Liana, 3-14 m alt.; caule cilíndrico, glabro ou puberulento, lenticelado. Estípulas não observadas; estipelas ausentes. Folhas 9-13-folioladas; imparipinadas, folíolos 2-6,1x0,9-2,8 cm, alternos, elípticos, base obtusa, ápice agudo a acuminado, face adaxial glabra, face abaxial pubérula, nervação broquidódroma. Cimeiras escorpióides, axilares; cálice 5-laciniado, 2-3 mm compr., campanulado, pubescente externamente, lacínios irregulares, agudos; corola 5-mera, creme, vexilo ca. $4 \mathrm{~mm}$ compr., alas 3,5-4 mm compr., pétalas da carena 3-4 mm compr.; androceu 9-mera, monadelfos, estames 2-4 mm compr.; gineceu estipitado, estípite 0,3-1 mm compr., ovário 0,7-1,5 mm compr., ciliado na margem superior, estilete ca. $1 \mathrm{~mm}$ compr., reto, glabro, estigma 
funiliforme, glabro. Fruto sâmara, 4,5-6,2x1,5-19 cm, oblongo-elíptico, plano, glabro, região seminífera central; 1-2 sementes; $0,8 \times 0,5 \mathrm{~cm}$, reniformes, castanhas.

Material examinado: BRASIL. Minas Gerais: Viçosa, EPTEA, Estrada para o Centro de Educação Ambiental, I/2002 (fl.), Lopes et al. 65 (VIC); Pedreira, VI/2005 (fr.) Rodrigues et al. 59 (VIC).

Possui hábito e folíolos muito variáveis, como evidencia o epíteto específico da sinonímia $D$. variabilis (CARVALHO, 1997). O material examinado da EPTEA apresentou flores com nove estames, uma variação não observada por Carvalho (1997); ainda assim, a espécie pôde ser reconhecida por apresentar cálice pubescente, com forma de lacínios semelhantes, sendo os dois laterais menores que os restantes. Carvalho (1997) propôs a divisão dessa espécie em duas variedades: var. frutescens e var. tomentosa, separadas morfologicamente por distinção no indumento dos caules jovens, pecíolos e raque de folhas e inflorescências. Não foi possível identificar a variedade presente na Estação, uma vez que o material amostrado apresentou uma sutil variação de indumento. Tal observação indica que talvez essa característica morfológica não seja suficiente para classificar a espécie em variedades. Na EPTEA, essa espécie ocorre na Estrada para o Centro de Educação Ambiental e sobre a Pedreira.

3. Dalbergia nigra (Vell.) Allemão ex Benth., J. Linn. Soc. 4(Suppl.): 36. 1860. Figuras 10-11.

Pterocarpus niger Vell., Fl. Flum. 299. 1829 [1825].

Árvore ca. $8 \mathrm{~m}$ alt.; caule cilíndrico, fissurado, viloso a glabrescente, lenticelado. Estípulas não observadas; estipelas ausentes. Folhas 15-23-folioladas, imparipinadas, folíolos1-2x0,4-1,3 cm, alternos, oblongos, base obtusa a retusa, ápice retuso, face adaxial pubérula ou glabrescente, face abaxial serícea ou pubescente e nervação broquidódroma. Cimeiras escorpióides, axilares; cálice 5-laciniado, ca. 6 mm compr., campanulado, lacínios irregulares, agudos, pubescentes externamente; corola 5-mera, creme esverdeada, vexilo ca. $8 \mathrm{~mm}$ compr., alas ca. $7 \mathrm{~mm}$ compr., pétalas da carena 5-6 mm compr.; androceu 10-mera, monadelfos, estames 5-6 mm compr.; gineceu estipitado, estípite ca. $3 \mathrm{~mm}$ compr., ovário ca. $2 \mathrm{~mm}$, ciliado em ambas as margens, estilete ca. 1,5 mm compr., geniculado, glabro, estigma funiliforme, glabro. Fruto sâmara, 4,5-9,5x1,3-1,7 cm, elíptico-oblongo, glabro, região seminífera central; 1-2 sementes, 0-9- 1x0,5-0,7 cm, oblongo-reniformes, castanho-escuras.

Material selecionado: BRASIL. Minas Gerais: Viçosa, EPTEA, Aceiro, IX/2001 (fr.), Garcia 862 \& Corrêa (VIC); “Caminho das Águas”, XI/2004 (fl.) Rodrigues 07 \& Garcia (VIC); VI/2005 (fr.), Rodrigues et al. 62 (VIC).

Essa espécie secaracteriza por apresentar folíolos oblongos, tubo do cálice glabro, lacínios pubescentes e ovário ciliado nas margens. As sâmaras castanho-escuras a vináceas também são características de $D$. nigra. $\mathrm{Na}$ EPTEA, esta é uma das espécies arbóreas encontradas com mais frequiência, ocorre em todas as trilhas amostradas, especialmente na Estrada para o Centro de Educação Ambiental e no aceiro. É uma árvore típica de Floresta Atlântica do Sul da Bahia, Norte do Espírito Santo, Minas Gerais e São Paulo (CARVALHO, 1997).

4. Erythrina falcata Benth., Fl. Bras. 15(1): 172. 1859. Figuras 12-14.

Árvore 20-25 m alt.; caule armado, cilíndrico, glabrescente, lenticelado. Estípulas ca. $5 \mathrm{~mm}$ compr., lineares, caducas; estipelas 1-2 mm compr., glanduliformes. Folhas 3-folioladas, folíolos laterais levemente assimétricos, $12,5-17,8 \times 5,8-9,7 \mathrm{~cm}$, folíolos terminais 13,3-18,8 x7-11,4 cm, elípticos, base obtusa, ápice levemente agudo, face adaxial glabrescente, face abaxial pubérula, nervação broquidódroma. Inflorescências racemosas, terminais; cálice não laciniado, 10-15 mm compr., campanulado, assimétrico, puberulento externamente; corola 5-mera, laranja-avermelhada, vexilo 4,2-4,5 cm compr., alas ca. 0,9 cm compr., pétalas da carena ca. 3,3 cm compr.; androceu 10-mera, diadelfos (9+1), estames 3,5-4,8 cm compr.; gineceu estipitado, estípite 7-9 mm compr., ovário ca. $15 \mathrm{~mm}$ compr., tomentoso, estilete 10-12 mm compr., levemente curvo, glabro, estigma funiliforme, barbado. Fruto não observado.

Material selecionado: BRASIL. Minas Gerais: Viçosa, EPTEA, “Trilha dos Gigantes", VII/ 2005 (fl.), Rodrigues 64 \& Stanciola (VIC).

Material adicional: BRASIL. Minas Gerais: Viçosa, Rua dos Estudantes, VIII/2005 (fl.), Rodrigues 65 (VIC).

E. falcata e Platycyamus regnellii são as duas espécies arbóreas trifolioladas da EPTEA e podem ser facilmente diferenciadas pelos caules armados e estipelas glandulares apresentadas pela primeira e que não ocorrem

R. Árvore, Viçosa-MG, v.31, n.3, p.521-532, 2007 
na segunda. Aúltima caracteriza-se também por apresentar estipelas glandulares, medindo ca. $2 \mathrm{~mm}$ compr. e corola laranja-avermelhada. É freqüente na "Trilha dos Gigantes", com indivíduos apresentando $20 \mathrm{~m}$ de altura ou mais. Espécie nativa da América do Sul, no Brasil ocorre no centro-sul, principalmente na Floresta Semidecídua de Altitude (KRUKOFF, 1939; LORENZI, 2002).

5. Hymenolobium janeirense Kuhlm. var. stipulatum (N. Mattos) Lima, Acta Amaz. 12(1): 45. 1982. Figuras 15-17.

Árvore 15-20 m alt.; caule cilíndrico, fissurado, lenticelado. Estípulas 4-7 mm compr., lanceoladas, estipelas ca. 1 mm compr., setáceas; Folhas 19-23folioladas; imparipinadas, folíolos 1,6-4x0,8-1,6 cm, opostos, oblongos, base retusa, ápice retuso a obcordado, face adaxial velutina ou lanosa, face abaxial serícea, nervação broquidódroma. Inflorescências paniculadas, terminais; cálice 5-laciniado, 5-8 mm compr., largamente campanulado, ferrugíneo-tomentoso ou velutino externamente, lacínios regulares, subtruncados; corola 5-mera, rosa claro, vexilo ca. 1,5 cm compr., rosa com mácula vinácea, alas e pétalas da carena 1,3-1,4 cm compr.; androceu 10-mera, monadelfos, estames 1-1,3 cm compr.; gineceu estipitado, estípite ca. 3,5 mm compr., ovário ca. $7 \mathrm{~mm}$ compr., ciliado na margem inferior, estilete ca. $3 \mathrm{~mm}$ compr., curvo, ciliado a glabro, estigma capitado, glabro. Fruto sâmara, 6,5-9,5x2,2-2,8 cm, oblongo-elíptico, cartáceo, glabro, região seminífera delimitada por duas nervuras submarginais; 1 semente, $1,5-1 \mathrm{~cm}$, falciforme, castanho-escura.

Material examinado: BRASIL. Minas Gerais: Viçosa, EPTEA, Aceiro, X/2001 (fl.), Lopes 29 \& Carvalho-Okano (VIC); X/2001 (fl.), Garcia 885 \& Corrêa (VIC); XII/2001 (fr.), Garcia et al. 912 (VIC).

Existem duas variedades para esta espécie: var. janeirense e var. stipulatum, que diferem apenas pela consistência e comprimento dos frutos (LIMA, 1982). Na variedade amostrada, a sâmara é cartácea, sendo, portanto, identificada como var. stipulatum. As estípulas medindo 5-7 mm de compr., estipelas presentes, persistentes e folíolos pubescentes em ambas as faces, são outras características que permitem o reconhecimento dessa variedade. É rara na EPTEA, onde foi localizado apenas um indivíduo no aceiro. Árvore ocasional nas formações florestais da região do Rio Doce, desde o nordeste de Minas Gerais até o noroeste do Espírito Santo (LIMA, 1982).

R. Árvore, Viçosa-MG, v.31, n.3, p.521-532, 2007
6. Machaerium brasiliense Vogel, Linnaea 11: 185. 1837. Figura 18.

Árvore ca. $10 \mathrm{~m}$ alt.; caule cilíndrico, fissurado, tomentoso a glabrescente, lenticelado. Estípulas até $3 \mathrm{~cm}$ compr., fundidas, elípticas, caducas; estipelas ausentes. Folhas 11-13-folioladas, imparipinadas, folíolos 2,7-5x0,7-2 cm, alternos, estreitos elípticos a elípticos, obovados ou oblanceolados, base obtusa a cuneada, ápice acuminado a cuspidado, ambas as faces tomentosas quando muito jovens a glabras quando velhas, tomentosas ao longo da nervura principal na face abaxial, nervação broquidódroma. Flor não observada. Fruto sâmara, 5-6,8x1-1,5 cm, cultriforme, glabro, região seminífera basal; 1 semente, 1-1,5x0,6 cm compr., oblongoreniforme, negra.

Material examinado: BRASIL. Minas Gerais: Viçosa, EPTEA, Aceiro, VIII/2001 (fr.), Garcia 859 \& Corrêa (VIC); X/2001 (fr.), Garcia 884 \& Corrêa (VIC); VI/2005 (fr.), Rodrigues et al. 57 (VIC).

M. brasiliense, dentre as espécies do gênero que apresentam porte arbóreo, é bem caracterizada por apresentar estípulas grandes, fundidas, caducas, protegendo as folhas quando muito jovens, folíolos sempre alternos, geralmente elípticos (SARTORI e TOZZI, 1998). Na EPTEA, essa espécie é muito freqüente no aceiro. Ocorre nos estados do Sudeste brasileiro (HOEHNE, 1941; MENDONÇAFILHO, 1996; SARTORI e TOZZI, 1998), em mata mesófila semidecídua, mata ciliar e cerradão (SARTORI e TOZZI, 1998).

7. Machaerium gracile Benth., Comm. Legum. Gen. 34. 1837. Figuras 19-20.

Liana ca. 2 m; caule cilíndrico, panoso a velutino, acinzentado, lenticelado. Estípulas 2-3 mm compr., espinescentes; estipelas ausentes. Folhas 31-41folioladas, imparipinadas, folíolos $0,8-1,2 \times 0,3-0,4 \mathrm{~cm}$, alternos, oblongos, base obtusa, ápice arredondado, mucronulado, face adaxial glabrescente, ciliada, face abaxial pubérula, discolores, nervação broquidódroma. Inflorescências racemosas, paniculadas (rara), axilares; cálice 5-laciniado, ca. 3 mm compr., campanulado, ferrugíneo-seríceo externamente, lacínios irregulares, reduzidos, agudos; corola 5-mera, alvo esverdeada, vexilo, alas e pétalas da carena ca. $5 \mathrm{~mm}$ compr.; androceu 10-mera, monadelfos, estames 3,5-5 mm compr.; gineceu estipitado, estípite 1,5-2 mm compr., ovário 1,5-2 mm compr., tomentoso, estilete ca. $1 \mathrm{~mm}$ compr., levemente 
curvo, glabro; estigma funiliforme, glabro. Fruto sâmara, 3-3,5x0,9-1,1 cm, cultriforme, glabrescente, região seminífera basal; 1 semente, ca. 2 cm compr., em forma de vírgula, plana, castanho-vinosa.

Material examinado: BRASIL. Minas Gerais: Viçosa, EPTEA, Estrada para o Centro de Educação Ambiental, I/2005 (fl., fr.), Rodrigues 20 (VIC).

$\mathrm{Na}$ área estudada, foi reconhecida, dentre as espécies que apresentam estípulas espinescentes, pelo seu porte: liana, ramos delgados, delicados, folhas 3141-folioladas e inflorescências axilares longas, delgadas, raramente ramificadas. Na EPTEA, foi localizado apenas um indivíduo às margens da estrada para o Centro de Educação Ambiental da Estação. No Brasil, ocorre nos Estados de Minas Gerais e Rio de Janeiro (HOEHNE, 1941; LIMA et al., 1994). É uma espécie muito rara e exclusiva da porção sudeste da Floresta Pluvial Atlântica (LIMA et al., 1994).

8. Machaerium hirtum (Vell.) Stellfeld, Tribuna Farm. 14 (12):246. 1946. Figuras 21-22

Nissolia hirta Vell., Fl. Flum. 296. 1829 [1825].

Árvore ca. 5 m. alt.; caule cilídrico, fissurado, glabrescente, lenticelado. Estípulas 3-5 mm compr., espinescentes, retilíneas; estipelas ausentes. Folhas 31-49-folioladas, imparipinadas, folíolos 1,3-2,3x0,3$0,6 \mathrm{~cm}$, alternos, estreito-oblongos, base oblíqua, ápice retuso, face adaxial glabra, face abaxial pubescente, discolores, nervação craspedódroma. Flor não observada. Fruto sâmara, 3,8-5,3x1,1-1,7 cm, cultriforme, esparsotomentosa, região seminífera basal; 1 semente, ca. 5 cm compr., reniforme, castanha.

Material examinado: BRASIL. Minas Gerais: Viçosa, EPTEA, “Caminho das Águas”, VI/2005 (fr.), Rodrigues 61 \& Stanciola (VIC).

O porte arbóreo, estípulas espinescentes retilíneas e folhas 31-49-folioladas com folíolos estreito-oblongos foram os caracteres vegetativos utilizados no reconhecimento de $M$. hirtum na área estudada. $\mathrm{Na}$ EPTEA é encontrada em locais perturbados, como próximo à lagoa principal da Reserva, e às margens da Estrada principal da Estação. No Brasil, ocorre nos Estados do Rio de Janeiro, Minas Gerais, São Paulo, Goiás, Espírito Santo e Paraná (MENDONÇA-FILHO, 1996;
SARTORI e TOZZI, 1998).

9. Machaerium nyctitans (Vell.) Benth., Comm. Legum. Gen. 34. 1837. Figuras 23-24.

Nissolia nictitans Vell., Fl. Flum. 295. 1829 [1825].

Árvore ca. 1,5 m alt.; caule estriado, tomentoso, viloso, glabrescente, lenticelado. Estípulas não observadas; estipelas ausentes. Folhas 17-23-folioladas, imparipinadas, folíolos 1,4-3,2 (3,8)x0,6-1,2 cm, alternos, oblongos, ovado-oblongos ou obovado-oblongos, base obtusa, ápice agudo a arredondado, face adaxial pubescente ou glabrescente, face abaxial ferrugíneotomentosa ou pubescente, discolores, nervação broquidódroma. Inflorescências paniculadas, terminais, ferrugíneo-tomentosas; cálice 5-laciniado, ca. $5 \mathrm{~mm}$ compr., campanulado, ferrugíneo-tomentoso externamente, lacínios irregulares, agudos; corola 5mera, róseo-vinosa, vexilo 8-9 mm compr., alas e pétalas da carena 7-8 mm compr.; androceu 10-mera, monadelfos, estames 5-7 mm compr.; gineceu estipitado, estípite 2-3mm compr.; ovário ca. 4mm compr., seríceo, estilete 1-2mm compr., curvo, glabro, estigma capitado, glabro. Fruto sâmara, 3,5-6,4x1-1,5 cm, cultriforme, ferrugíneopubescente a glabrescente, região seminífera basal; 1 semente, 8x3-4 mm, oblongo-reniforme, castanhoescura.

Material examinado: BRASIL. Minas Gerais: Viçosa, EPTEA, Aceiro, VIII/2001 (fr.), Garcia et al. 850 (VIC); Estrada para o Centro de Educação Ambiental, V/2005 (fl.), Rodrigues 47 \& Basílo (VIC); Aceiro, VI/ 2005 (fr.), Rodrigues et al. 55 (VIC).

Embora Lima et al. (1994), tenham mencionado que $M$. nyctitans é uma espécie muito variável quanto à morfologia e ao indumento das folhas, na EPTEA ela é facilmente reconhecida, entre as espécies arbóreas, por apresentar indumento ferrugíneotomentoso revestindo a face abaxial dos folíolos e as inflorescências paniculadas terminais. Na EPTEA, ocorre em locais abertos e perturbados, como as margens da estrada para o Centro de Educação Ambiental e no aceiro. No Brasil, ocorre nos Estados da Bahia, Santa Catarina, Paraná e Região Sudeste (LIMA et al., 1994). Espécie amplamente distribuída na Floresta Pluvial Atlântica e na Floresta Estacional do planalto meridional (LIMA et al., 1994).

R. Árvore, Viçosa-MG, v.31, n.3, p.521-532, 2007 
10. Ormosia vicosana Rudd, Contr. U.S. Natl. Herb. 32(5):315, f.4. 1965. Figuras 25-26

Árvore ca. 15 m. alt.; caule fulvo ou ferrugíneotomentoso a viloso ou glabrescente. Estípulas não observadas, caducas; estipelas ausentes. Folhas 911-folioladas, imparipinadas, folíolos 2-4,2(5,5)x4,7$9,5(10) \mathrm{cm}$, opostos, oblongo-elípticos a obovados, base cuneada, ápice agudo a levemente acuminado, face adaxial glabra, face abaxial glabrescente, nervura central esparso-tomentosa, discolores, nervação broquidódroma. Flor não observada. Fruto legume 1,72,3x4-7 cm, indeiscente a tardiamente deiscente, lenhoso a sublenhoso, ferrugíneo-velutino; 1-2 sementes, 1,1$1,3 \mathrm{~cm}$ diâmetro, elipsóides, bicolores vermelhas e pretas.

Material examinado: BRASIL. Minas Gerais: Viçosa, EPTEA, Aceiro, VI/2005 (fr.), Rodrigues 60 \& Stanciola (VIC).

$O$. vicosana é semelhante a $O$. minor, da qual difere pelo número e pela forma dos folíolos; o fruto é não rugoso e as nervuras, secundárias moderadamente pronunciadas (RUDD, 1954). Na EPTEA, é facilmente distinguida por apresentar sementes bicolores. Embora a descrição desta espécie mencione a presença de frutos apenas monospérmicos (RUDD, 1954), o exemplar amostrado na EPTEA possui também frutos dispérmicos; espécie com rara ocorrência na área estudada, sendo representada apenas por um indivíduo na trilha do aceiro. Esta espécie é considerada endêmica de Viçosa, Minas Gerais (RUDD, 1954).

11. Platycyamus regnellii Benth., Fl. Bras. 15(1): 323. 1862. Figuras 27-28

Árvore ca. $17 \mathrm{~m}$ alt.; caule cilíndrico, puberulento a glabrescente, lenticelado. Estípulas e estipelas não observadas, caducas. Folhas 3-folioladas, folíolos laterais assimétricos, 11,5-21 x5,3-13,5 cm, folíolos terminais, 14-22,4x6,5-14 cm, ovados, base obtusa a cuneada, ápice agudo, face adaxial pubérula a glabra, face abaxial pubescente, nervação broquidódroma. Inflorescências paniculadas, terminais; cálice 5-laciniado, 1,5-1,8 cm compr., campanulado, ferrugíneo-velutino externamente, lacínios irregulares, agudos; corola 5-mera, violácea quando jovem, tornando-se esbranquiçada após a antese, vexilo18-21 mm compr., alas 19-23 mm compr., pétalas da carena 22-25 mm compr.; androceu 10-mera, diadelfos (9+1), estames 18-22 mm compr.; gineceu séssil, ovário
10-11 mm compr., viloso, estilete 10-12 mm compr., seríceo na base a glabro no ápice, estigma capitado, glabro. Legume não observado.

Material examinado: BRASIL. Minas Gerais: Viçosa, EPTEA, Estrada para o Centro de Educação Ambiental, III/2005 (fl.), Rodrigues 37 \& Batista (VIC).

Essa espécie, juntamente com E. falcata, são as duas espécies arbóreas trifolioladas da EPTEA, diferenciadas por caracteres descritos anteriormente nos comentários da segunda. Os caracteres utilizados na identificação de Platycyamus regnellii foram as folhas trifolioladas, inflorescências em panículas terminais e corola violácea no botão, esbranquiçada após a antese. Na EPTEA, é encontrada na margem da Estrada para o Centro de Educação Ambiental. Distribui-se nos Estados de Goiás, sul da Bahia, Espírito Santo, Minas Gerais e São Paulo, principalmente na floresta semidecídua de altitude (LORENZI, 2002).

12. Platypodium elegans Vog., Linnaea 11: 422. 1837. Figuras 29-30

Árvore $16 \mathrm{~m}$ alt.; caule estriado, puberulento, lenticelado. Estípulas ca. $2 \mathrm{~mm}$ compr., triangulares, caducas; estipelas ausentes. Folhas 13-19-folioladas, imparipinadas, folíolos 1,8-3,7(4,4)x0,8-1,5(1,8) cm, alternos, oblongos, raramente obovados, base obtusa, ápice obcordado, face adaxial glabra, face abaxial esparsoserícea, discolores, nervação camptódroma. Flor não observada. Fruto sâmara 8,5-10,9x2,2-3 cm, glabra, região seminífera distal; 1 (raro 2) sementes, $1,1 \times 0,4 \mathrm{~cm}$, irregular, vinácea.

Material examinado: BRASIL. Minas Gerais: Viçosa, EPTEA, Estrada para o Centro de Educação Ambiental, VI/2005 (fr.), Rodrigues 63 \& Stanciola (VIC).

Essa espécie pode ser diferenciada das demais espécies arbóreas por apresentar os folíolos alternos, oblongos com ápice obcordado e nervação proeminente em ambas as faces dos folíolos, sendo as nervuras secundárias paralelas ascendentes: nervação camptódroma. Na EPTEA, é freqüentemente encontrada às margens de trilhas, da estrada para o Centro de Educação Ambiental, no aceiro e interior de mata. No Brasil, ocorre do Piauí até Goiás, Mato Grosso do Sul e São Paulo, principalmente no Cerrado (LORENZI, 2002). 


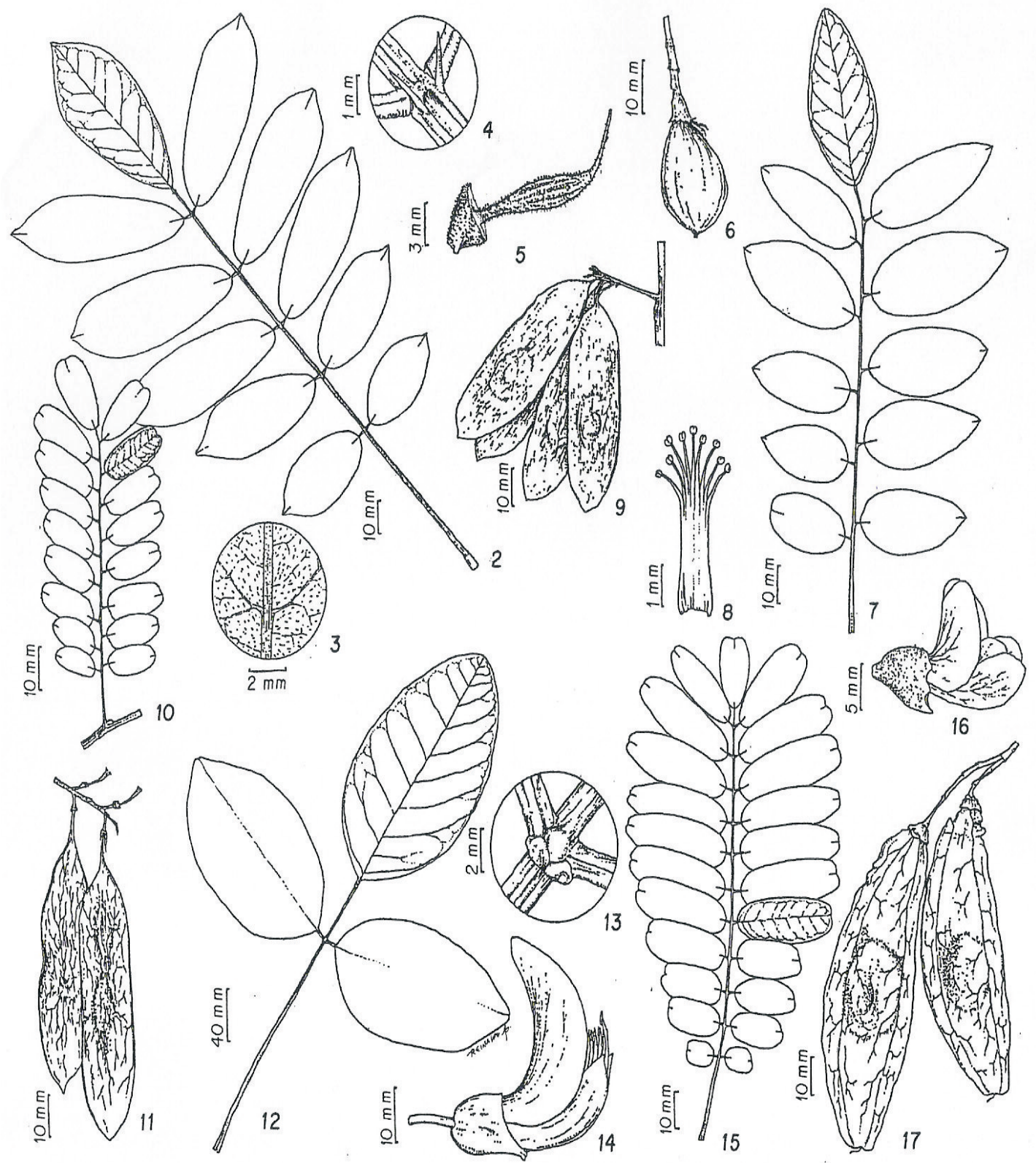

(Ilustrações: Reinaldo A. Pinto)

Figuras 2-6 - Andira fraxinifolia: 2. Folha, 3. Face abaxial do folíolo, 4. Estipelas, 5. Gineceu, 6. Fruto (Rodrigues \& Basílio 12 e Rodrigues \& Ferreira 36). Figuras 7-9. Dalbergia frutescens: 7. Folha, 8. Androceu, 9. Frutos (Lopes et al. 65 e Rodrigues et al.59). Figuras 10-11. Dalbergia nigra: 10. Folha, 11. Fruto (Garcia \& Corrêa 862). Figuras 12-14. Erythrina falcata: 12. Folha, 13. Estipelas, 14. Flor (Rodrigues \& Stanciola 64 e Rodrigues 65). Figuras 15-17. Hymenolobium janeirense var. stipulatum: 15. Folha, 16. Flor, 17. Frutos (Garcia et al. 912 e Garcia \& Corrêa 885).

Figures 2-6-Andira fraxinifolia: 2.Leaf, 3. Abaxial surface of leaflet, 4. Stipels, 5. Ginoecium, 6. Fruit (Rodrigues \& Basílio 12 e Rodrigues \& Ferreira 36). Figures 7-9. Dalbergia frutescens: 7. Leaf, 8. Androecium, 9. Fruits (Lopes et al. 65 e Rodrigues et al.59). Figures 10-11. Dalbergia nigra: 10. Leaf, 11. Fruit (Garcia \& Corrêa 862). Figures 12-14. Erythrina falcata: 12. Leaf, 13. Stipels, 14. Flower (Rodrigues \& Stanciola 64 e Rodrigues 65). Figures 15-17. Hymenolobium janeirense var. stipulatum: 15. Leaf, 16 Flower, 17. Fruits (Garcia et al. 912 e Garcia \& Corrêa 885).

R. Árvore, Viçosa-MG, v.31, n.3, p.521-532, 2007 


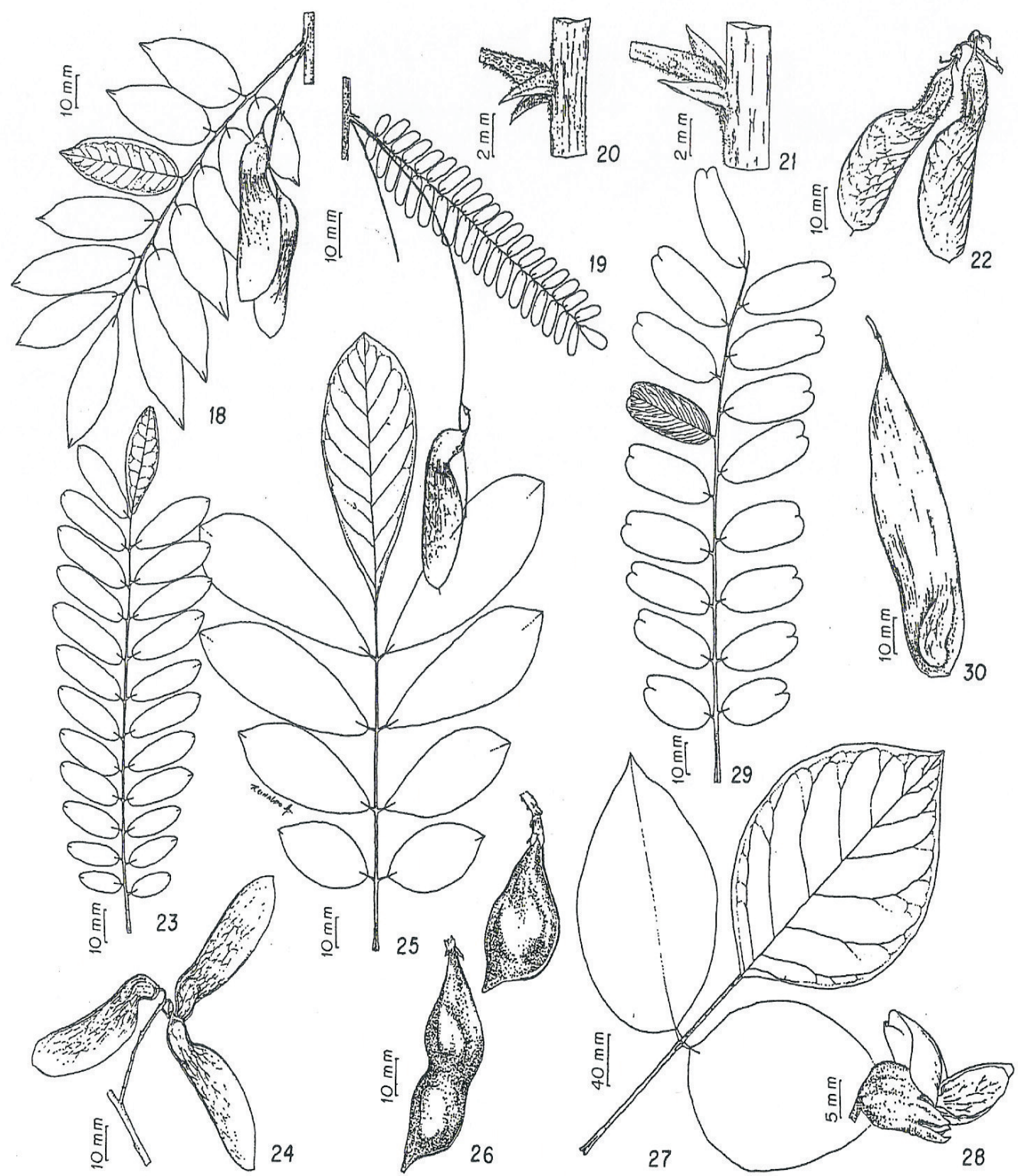

(Ilustrações: Reinaldo A. Pinto)

Figura 18 - Machaerium brasiliense: 18. Ramo com folha e frutos. (Rodrigues et al. 57). Figuras 19-20. Machaerium gracile: 19. Ramo com folha e fruto, 20. Estípulas espinescentes (Rodrigues 20). Figuras 21-22. Machaerium hirtum: 21. Estípulas espinescentes, 22. Frutos (Rodrigues \& Stanciola 61). Figuras 23-24. Machaerium nyctitans: 23. Folha, 24. Frutos (Garcia et al. 850 e Rodrigues \& Basílio 47). Figuras 25-26. Ormosia vicosana: 25. Folha, 26. Frutos (Rodrigues \& Stanciola 60). Figuras 27-28. Platycyamus regnellii: 27. Folha, 28. Flor (Rodrigues \& Batista 37). Figuras 29-30. Platypodium elegans.: 29. Folha, 30. Fruto (Rodrigues \& Stanciola 63).

Figure 18 -Machaerium brasiliense: 18. Branch with leaf and fruits. (Rodrigues et al. 57). Figures 19-20. Machaerium gracile: 19. Branch with leaf and fruit, 20. Spinescent stipules (Rodrigues 20). Figures 21-22. Machaerium hirtum: 21. Spinescent stipules, 22. Fruits (Rodrigues \& Stanciola 61). Figures 23-24. Machaerium nyctitans: 23. Leaf, 24. Fruits (Garcia et al. 850 e Rodrigues \& Basílio 47). Figures 25-26. Ormosia vicosana: 25. Leaf, 26. Fruits (Rodrigues \& Stanciola 60). Figures 27-28. Platycyamus regnellii: 27. Leaf, 28. Flower (Rodrigues \& Batista 37). Figures 29-30. Platypodium elegans: 29. Leaf, 30. Fruit (Rodrigues \& Stanciola 63).

R. Árvore, Viçosa-MG, v.31, n.3, p.521-532, 2007 


\subsection{Considerações finais}

O levantamento comprovou a grande representatividade específica de Papilionoideae dentre as espécies arbóreas e lianas da EPTEA, Mata do Paraíso.

Das trilhas estudadas, a Estrada para o Centro de Educação Ambiental e a trilha do aceiro foram as que apresentaram maior número de espécies, sete em ambas.

Dalbergia nigra, o jacarandá-da-baía, destacouse como uma das espécies que ocorrem mais freqüentemente na Estação e, por apresentar um histórico de intensa exploração de sua madeira e ocorrência restrita na Floresta Atlântica, foi incluída como vulnerável na Lista Vermelha de Espécies Ameaçadas de Extinção da Flora de Minas Gerais (2000). Ormosia vicosana, espécie endêmica da região de Viçosa (RUDD, 1954), foi amostrada como espécie rara, na Mata. Essas observações comprovam a importância da conservação da biodiversidade da vegetação da EPTEA, Mata do Paraíso.

\section{AGRADECIMENTOS}

Ao CNPq, pela concessão da bolsa de IC; ao Departamento de Biologia Vegetal, pela infra-estrutura; ao funcionário do Departamento de Engenharia Florestal Joel Stanciola, pelo auxílio nas coletas; e ao Reinaldo Antônio Pinto pelas ilustrações.

\section{REFERÊNCIAS}

BARROSO, G. M. et al. Sistemática das angiospermas do Brasil. Viçosa, MG: Universidade Federal de Viçosa, 1991. v.3. 326p.

CARVALHO, A. M. A synopsis of the genus Dalbergia (Fabaceae, Dalbergieae) in Brazil. Brittonia, v.49, n.1, p.87-109, 1997.

CASTRO, P. S. Influência da cobertura florestal na qualidade da água em duas bacias hidrográficas da região de Viçosa, MG. 1980. 189f. Dissertação (Mestrado em Engenharia Florestal)- Escola Superior de Agronomia de Luíz de Queiroz, Piracicaba, 1980.

CORRÊA, I. M.; GARCIA, F. C. P. Levantamento Florístico das Caesalpinioideae (Leguminosae) na Reserva Florestal do Paraíso, Viçosa, MG. In: CONGRESSO NACIONAL DE BOTÂNICA, 54., 2003, Belém. Anais ... Belém: Sociedade Brasileira de Botânica, 2003. CD- ROM.
DRUMMOND, G. M. et al. Biodiversidade em Minas Gerais: um atlas para sua conservação. Belo Horizonte: Fundação Biodiversitas, 2005. 222p.

FIDALGO, O.; BONONI, V. L. R. Técnicas de coleta, preservação e herborização de material botânico. São Paulo: Instituto de Botânica, 1989. 62p.

HOEHNE, F. C. Leguminosas-Papilionadas: gêneros Machaerium e Paramachaerium. In: HOEHNE, F. C. (Ed.). Flora Brasilica. São Paulo: Romiti \& Lanzara, 1941. p.1-99.

KRUKOFF, B. A. The American species of Erythrina. Brittonia, v.3, n.2, p.205-337, 1939.

LEAL-FILHO, N. Caracterização do banco de sementes de três estádios de uma sucesssão vegetal na Zona da Mata de Minas Gerais. 1992. 116f. Dissertação (Mestrado em Ciência Florestal) - Universidade Federal de Viçosa, Viçosa, MG, 1992.

LESSA, G. et al. Caracterização e monitoramento da fauna de pequenos mamíferos terrestres de um fragmento de mata secundária em Viçosa, Minas Gerais. Revista Bios, v.7, n.7, p.41-49, 1999.

LEWIS, G. P. Legumes of Bahia. Kew: Royal Botanical Gardens, 1987. 369p.

LEWIS, G. P. et al. Legumes of the world. Kew: Royal Botanical Gardens, 2005. 577p.

LIMA, H. C. Considerações taxonômicas sobre o gênero Hymenolobium Bentham (LeguminosaeFaboideae). Acta Amazônica, v.12, n.1, p.41-48, 1982.

LIMA, H. C.; CORREIA, C. M. B.; FARIAS, D. S. Leguminosae. In: LIMA, M. P. M.; GUEDESBRUNI, R. R. (Ed.). Reserva Ecológica de Macaé de Cima: Nova Friburgo - RJ: aspectos florísticos das espécies vasculares. Rio de Janeiro: Jardim Botânico do Rio de Janeiro, 1994. v.1.p.167-228.

LORENZI, H. Árvores brasileiras: manual de identificação e cultivo de plantas arbóreas nativas do Brasil. 4. ed. São Paulo: Plantarum, 2002. v.1. 368p.

R. Árvore, Viçosa-MG, v.31, n.3, p.521-532, 2007 
MARANGON, L. C.; SOARES, J. J.; FELICIANO, A. L. P. Florística Arbórea da Mata da Pedreira, município de Viçosa, Minas Gerais. Revista Árvore, v.27, n.2, p.207-215, 2003.

MEIRA-NETO, J. A. A.; MARTINS, F. R.

Composição florística do estrato herbáceo-arbustivo de uma floresta estacional semidecidual em ViçosaMG. Revista Árvore, v.24, n.4, p.407-416, 2000.

MEIRA-NETO, J. A. A.; MARTINS, F. R. Composição florística de uma floresta estacional semidecidual Montana no município de Viçosa-MG. Revista Árvore, v.26, n.4, p.437-446. 2002.

MENDONÇA, M. P.; LINS, L. V. Lista vermelha das espécies ameaçadas de extinção da flora do estado de Minas Gerais. Belo Horizonte: Fundação Biodiversitas, Fundação ZooBotânica de Belo Horizonte, 2000. 160p.

MENDONÇA-FILHO, C. V.; BRAGA, P. I. S. Espécies de Machaerium Pers. (LeguminosaePapilionoideae) da Estação Biológica de Caratinga (EBC). Daphne, v.6, n.3, p.77-84, 1996.

PENNINGTON, R. T. Monograph of Andira (Leguminosae-Papilionoideae). Systematic Botany Monographs, v.64, p.1-143, 2003.

POLHILL, R. M. Papilionoideae. In: POLHILL, R. M.; RAVEN, P. H. (Ed.). Advances in Legume Systematics part I. Kew : Royal Botanic Gardens, 1981. p.191-208.

RADFORD, A. E. et al.Vascular plant systematics. New York: Harper \& Row, 1974. 891p.

RIZZINI, C. T. Tratado de fitogeografia do Brasil: aspectos ecológicos, sociológicos e florísticos. São Paulo: Âmbito Cultural, 1992.747p.
RUDD, V. E. The American species of Ormosia (Leguminosae). Contributions from the National Herbarium, v.32, n.5, p.279-388, 1954.

SARTORI, A. L. B.; TOZZI, A. M. G. A. As espécies de Machaerium Pers. (LeguminosaePapilionoideae-Dalbergieae) ocorrentes no estado de São Paulo. Revista Brasileira de Botânica, v.21, n.3, p.211-246, 1998.

SILVA, A. F.; FONTES, N. R. L.; LEITÃO-FILHO, H. F. Composição florística e estrutura horizontal do estrato arbóreo de um trecho da Mata da Biologia da Universidade Federal de Viçosa- Zona da Mata de Minas Gerais. Revista Árvore, v.24, n.4, p.397-405, 2000.

SILVA, A. F. et al.Composição florística e grupos ecológicos das espécies de um trecho de floresta semidecídua submontana da Fazenda São Geraldo, Viçosa- MG. Revista Árvore, v.27, n.3, p.311-319, 2003.

VELOSO, H. P.; RANGEL-FILHO, A. L. R.; LIMA, J. C. A. Classificação da vegetação brasileira, adaptação a um sistema Universal. Rio de Janeiro: Fundação Instituto Brasileiro de Geografia e Estatística, 1991. 123p.

VOLPATO, M. M. L. Regeneração natural em uma floresta secundária no domínio da Mata Atlântica: uma análise fitossociológica. 1994. 123f. Dissertação (Mestrado em Ciência Florestal)Universidade Federal de Viçosa, Viçosa, MG, 1994.

WOJCIECHOWSKI, M. F. Recontructing the phylogeny of legumes (Leguminosae): an early 21 st century perspective. In: KLITGAARD, B. B.; BRUNEAU. A. (Ed.). Advances in legume systematics 10. Kew : Royal Botanic Gardens, 2003. p.5-35. 